
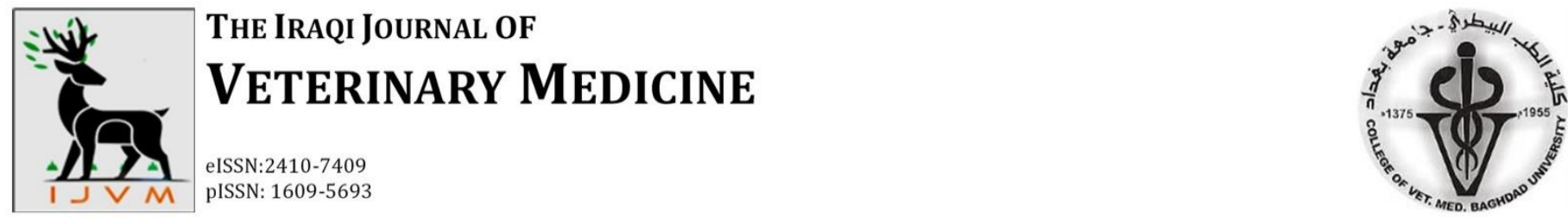

OPEN ACCESS

\title{
The Arterial Vascularization of the Small and Large Intestine in Adult Male Turkeys (Meleagris gallopavo)
}

\author{
Rabab Naser ${ }^{*} \oplus$, and Iman M Khaleel ${ }^{2}$ \\ ${ }^{1}$ Department. of Anatomy and Histology, College of Veterinary Medicine, Diyala University, Iraq, \\ ${ }^{2}$ Department. of Anatomy and Histology, College of Veterinary Medicine, University of Baghdad, Iraq
}

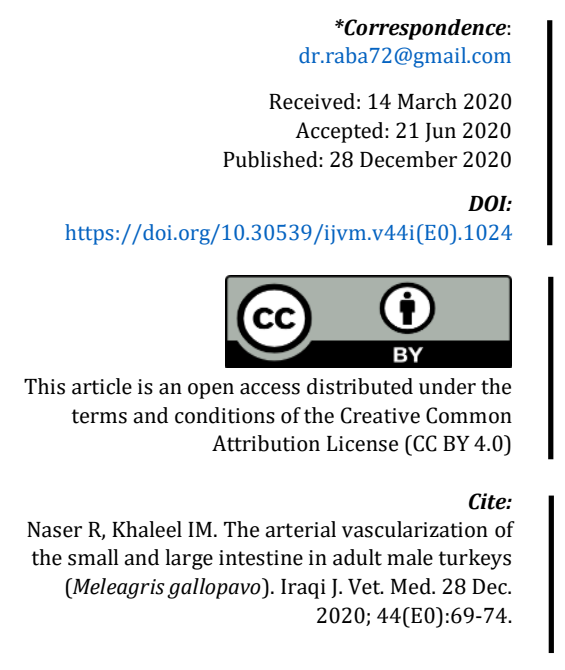

${ }^{*}$ Correspondence:
dr.raba72@gmail.com

Received: 14 March 2020 Accepted: 21 Jun 2020

DOI: . 
birds received the blood by main arteries raised from ascending aorta including cranial mesenteric artery and caudal mesenteric artery in goose and chicken (16), in the cattle egret (Bubulcus ibis) (17) in White -eared bulbul (pycnonotus leucotus (18), in pigeon (Columba Livia domestica) and in Iraqi mallard (Anasplatyrhynchos) $(9,8)$. The aim of the study was to reveal the blood supply of the intestinal tract (small and large) intestine in bronze male adult turkey

\section{MAterials AND MethodS}

All procedures conducted in this study was reviewed and approved by the scientific committee in the College of Veterinary Medicine, University of Baghdad in accordance with the ethical standards of animal welfare.

The study included five healthy adult male turkeys (Meleagris gallopav) to study the blood supply in intestine canal). These birds were purchased from a local supplier in Diyala city, Iraq. The birds were collected in the period between March to October 2019. All birds were euthanized by lethal dose injection of xylazine (Rompum ${ }^{\circledR}$ ) of does 10 $\mathrm{mg} / \mathrm{kg} \mathrm{BW}$ with Ketamin $15 \mathrm{mg} / \mathrm{kg}$ BW (19). The skin and the muscle of the thorax were removed, and the sternum was cut by bone cutter to expose the heart and subsequently the left ventricle was opened, and catheter was inserted in it for evaculating the blood then injected with gum milk latex colored with carmin pigment Rotring ${ }^{\circledR}$ for coloring the arteries. After 24 hours, the specimen kept in $10 \%$ formaline solution, after that the coelomic cavity was opened and the specimens dissected very carefully to

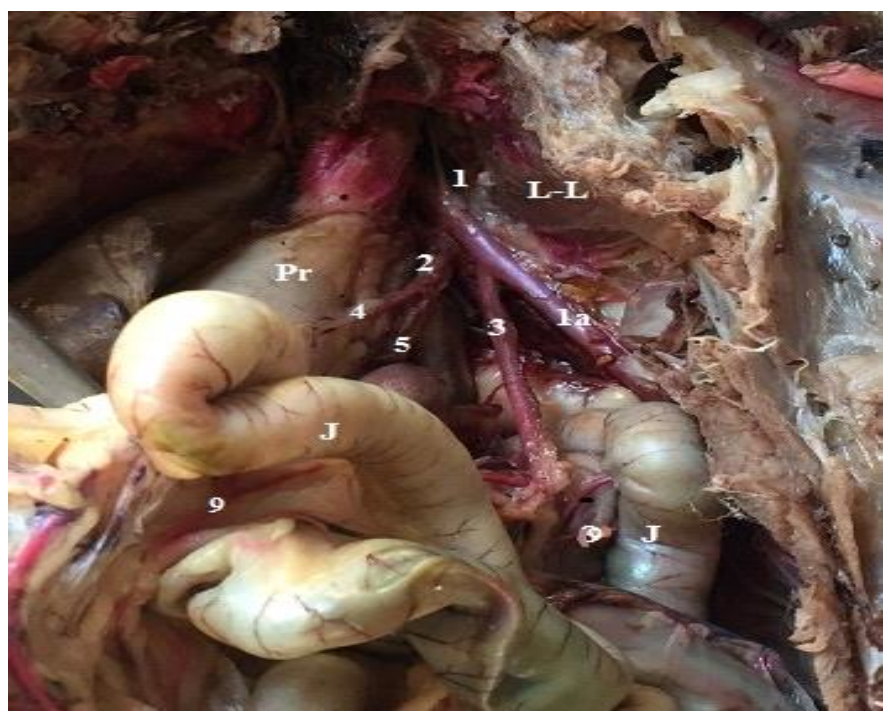

Figure 1. Photograph illustrates the blood supply of intestinal tract. 1: Aorta, 1a: Descending aorta, 2: Celiac a, 3:Cranialmesenteric a.,4:Left ramus a., 5: Right ramus .9:Jejunal a. J :Jejunum, Pr: Proventiculus ,S: Spleen, L-L: left lung. study the arteries that supplied small and large intestine. The obtained results were photographed using Sony digital camera 5 mega pixels.

\section{RESULTS}

This small and large intestine showed to be supplied by three major arteries namely: celiac, cranial mesenteric, and caudal mesenteric arteries. They were raised from descending aorta. Generally, at the level of fifth ribs, it gave off unpaired visceral arteries which were distributed in the stomach, pancreas, liver, spleen and segments of small intestine. Caudal mesenteric artery supplied the distal part of small intestine (ileum), large intestine (rectum and two caeca) and cloaca (Figures 1, and 2).

\section{Celiac Artery}

Generally, the celiac artery was the main artery arose from the right aspect of descending aorta which supplied the proventiculus, gizzard and duodenum, pancreas, jejunum, liver, spleen, and it splited at the caudal border of liver into small left ramus artery and larger right ramus artery (Figures 1, and 2). The Celiac artery included two ramus, the left ramus and right ramus. The left ramus of the celiac artery passes along the left side of the proventiculus then it nourished the spleen and glandular stomach (Figure 2 ). The right ramus of the celiac gave off gastroduodenal, jejunal and one or more substantial ileocecal arteries. It extended dorsally to the distal ileum

and cecum and it continued as the pancreatioduodenal (Figures 2, and 3).

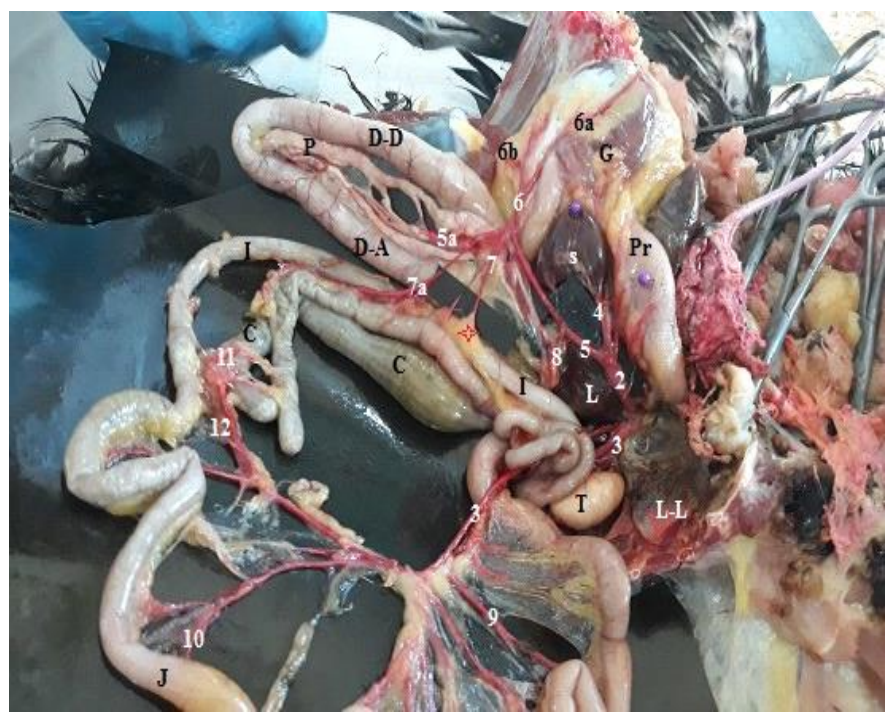

Figure 2. Photograph illustrates arterial blood supply of small intestine, 2: Celiac, 3:Cranial mesenteric a. ,4: left ramus, 5:right ramus am, 5a.:pancreatico-duodenal a. , $6 a, 6 b$ :right and left gastro duodenal a.,7:7a: ileocecal a, 8,9 : jejunal a.,10:marginaintestinal artery 11:ilial a.: s: spleen ,G:Gizzard ,Pr :proventiculus, D: duodenum (D-D\&D-A; descending\& ascending duodenum), J : Jejunum, I-ileum, C:cecum. ,L-L :left lung , T:testis ,L: liver, red stare: ileocecal ligament 


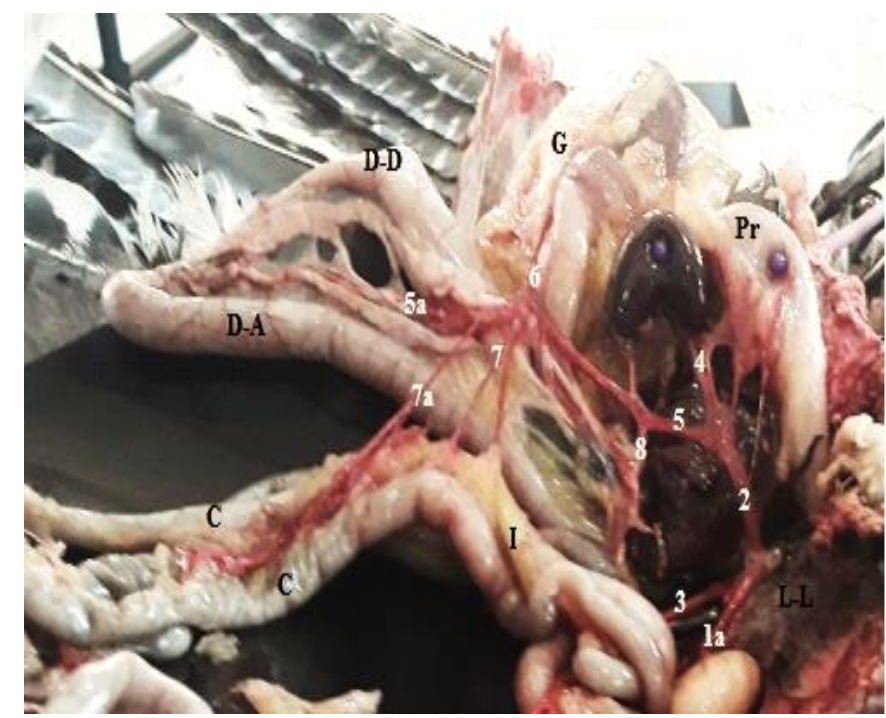

Figure 3. Photograph illustrates,1a :green arrow descending aorta, 2:celiac a.,3: Cranial mesenteric a.:4:Left ramus a.,5:right ramus a.,5a: Pancreaticoduodenal a.,6: gastroduodenal artery 7,7a :ileocecal a(ilial a., cecal a.).8: jejunala.Pr: Proventriculus, A- D\& D-D: ascending and descending duodenu m, C: ceca, G-Gizzard,L-L :left lung

\section{Celiac Right Ramus}

The celiac right ramus branches included:

A. Gastroduodenal artery: It was short artery; arose from the right ramus artery and it is split into 2-3 small branches that supplied the gizzard (Figure 2).

B. Jejunal artery: Short branch arises from celic artery at the caudal pole of spleen, it was supplied the proximal part of the jejunum (Figure 2).

C. Pancreatoduodenal artery: This artery considered as the continuous of the right ramus artery, entered between the descending limb and ascending limb of the duodenum which gave series branches on each side of both limbs of duodenum and distributed in all lobes of the pancreas (Figures 2, 3, and 4).

D. Ileocecal Artery: There are two to three branches that arose from right ramus of celiac artery, these arteries pass through the ileocecal ligament. It supplied the caudal third portion of the ileum, cecum and anastomosed with the ileocecal artery which originated from the cranial mesenteric artery (Figures 2, 3, and 4).

\section{Cranial Mesenteric Artery}

Cranial mesenteric artery was the second large artery originated from descending aorta to supplied jejunum (Figures 1, and 2), ileum and two ceca (Figure 2).

The branches of the cranial mesenteric artery:

A. Duodenojejunal artery: It is the largest branch that arose from cranial mesentery artery passing through mesentery which supplied the terminal part of the duodenum and the initial portion of jejunum at the duodeno-jejunal flexure (Figures 2, 4, and 5).

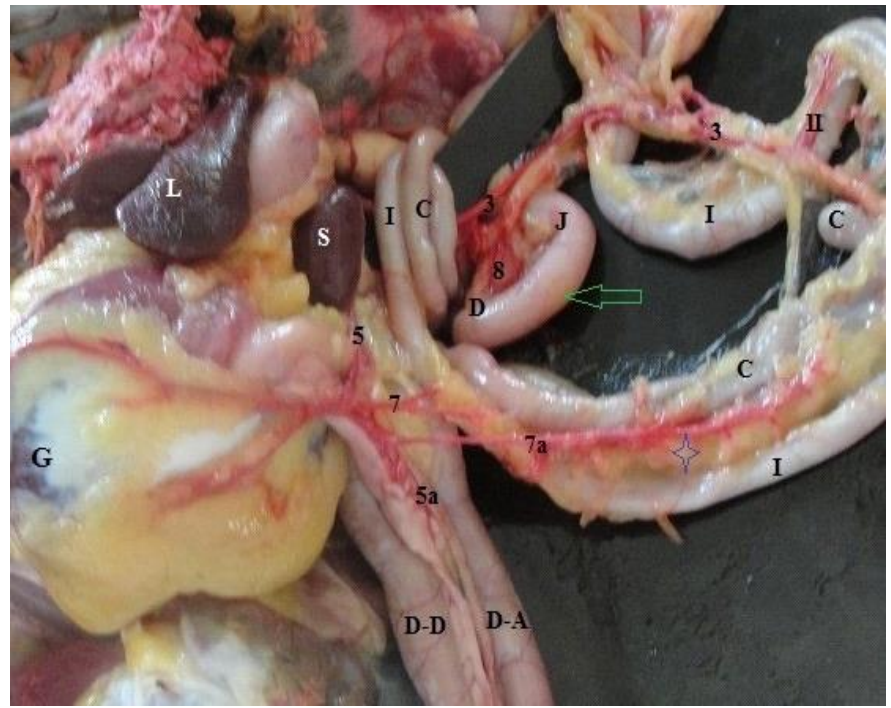

Figure 4. Photograph illustrates the branches of the celiac artery,3: cranial mesenteric artery; 5: Right celiac a. 5a: pancreaticoduodenal ,7,7a : ileocecal branches a.,7\&7a:cecalbranchs, 8: jejunal a.; 11: ileal a. A-D\& D-D: ascending and descending duodenum, $\mathrm{C}$

B. Jejunal arteries: It was a group of arteries, included seven-ten in various sizes of jejunal arteries to these arteries continuous to reach the large intestinal (two ceca) then anastomosed with the ileocecal artery of the celiac artery (right ramus) passing along the mesentery of jejunum that supplied last part of the jejunum and the first part of the ileum, each one of jejunal artery split into two small primary branches which anastomosed with another branches of adjacent arteries supplied each side of jejunal wall (Figures 2, 6, and 7).

C. Ileal artery: The small branch originated from terminal portion of the cranial mesenteric artery supplied the jejunum and ileum then it anastomosed with ileo-cecal branch of the celiac artery (Figures 6, and 7).

D. Iliocecal artery: The ileum and the two ceca passed in parallel direction. They are nourished by last branch of the cranial mesenteric artery (ileocecal branches) (Figure 7).

The ileum was near the ileocecal junctions which was supplied by anastomotic branches of the celiac and cranial mesenteric arteries (Figure 6), The ileal arteries of cranial mesenteric artery anastomosed with the ileocecal branches from pancreatico-duodenal artery (Figure 7).

\section{Caudal Mesenteric Artery}

It is short branch arose from the aorta at the level of caudal lobe of the left kidney suppling the ileum, rectum, and all segments of the ceca with arteries that originated from the cranial mesenteric artery (Figure 8). it is divided into two groups of arteries, cranial and coudal groups. The cranial group arteries consisted of 7-8 branches extended 
on the dorsal aspect of the ceca, distal ileum, and cranial rectum. The branches passed cranially and anastomosed with the ileocecal artery branch of celiac artery (Figure 8).

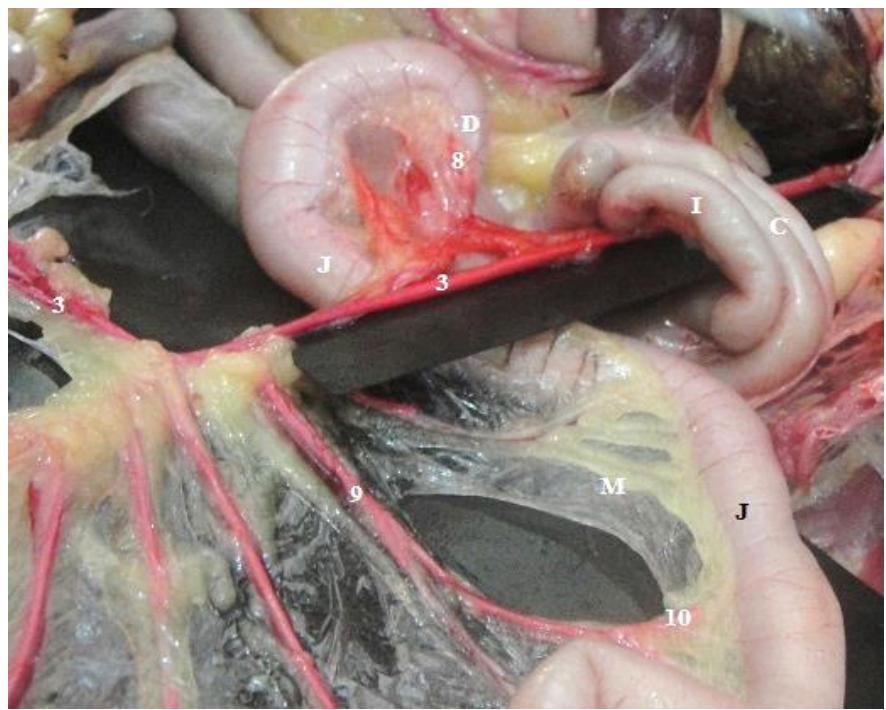

Figure 5. Photograph illustrates arterial blood supply of jejunum in male turkey, 3 : Cranial mesenteric a.,9:jejunal a. ,10: marginal intestinal a. , D: duodenum j : jejunum ,I :ileum, green arrow duodenal-jejunal flexure ,M: Mesentery

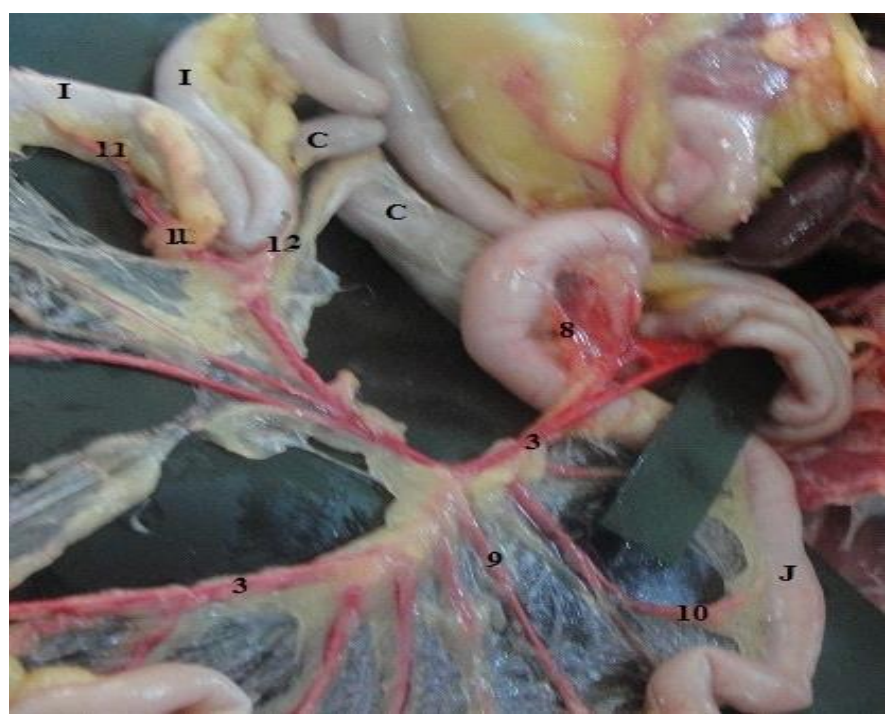

Figure 7. Photograph illustrates blood supply of the J: jejunum ,I: ileum ,C: cecae ,3: cranial mesenteric a , 8,9: jejunal artery, 10 :marginal intestinal artery, 11:ilealartery ,12:Cecal a.

\section{DISCUSSION}

The descending aorta gave of unpaired arteries (celiac and cranial mesenteric) at the caudal border of the lung that supplied the muscular and glandular stomach, duodenum, jejunum, ileum, cecum, pancreas, liver, and spleen. This result was in agreement with (3-6) in fowl, (10) in red falcon (Phoenicopterus roseus), (14) in greater flamingo,
The caudal groups consisted of 3-5 branches that supplied the distal part of rectum and cloaca (Figures 8 , and 9). The caudal mesenteric artery ramified with cranial mesenteric artery (Figure 9).

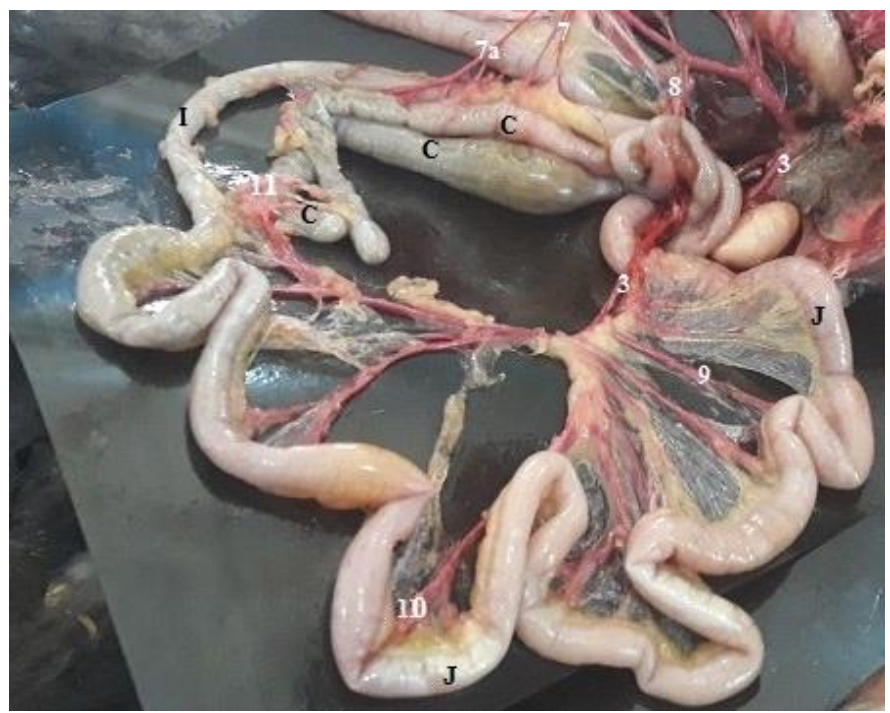

Figure 6. Photograph illustrate blood supply of the jejunum, I:ileum, C:ceca 3:cranial mesenteric a ,7,7a:ileocecal arteries, 11:cecal branch fromjejunal a. 9:jejunal branches a.10:marginal a.

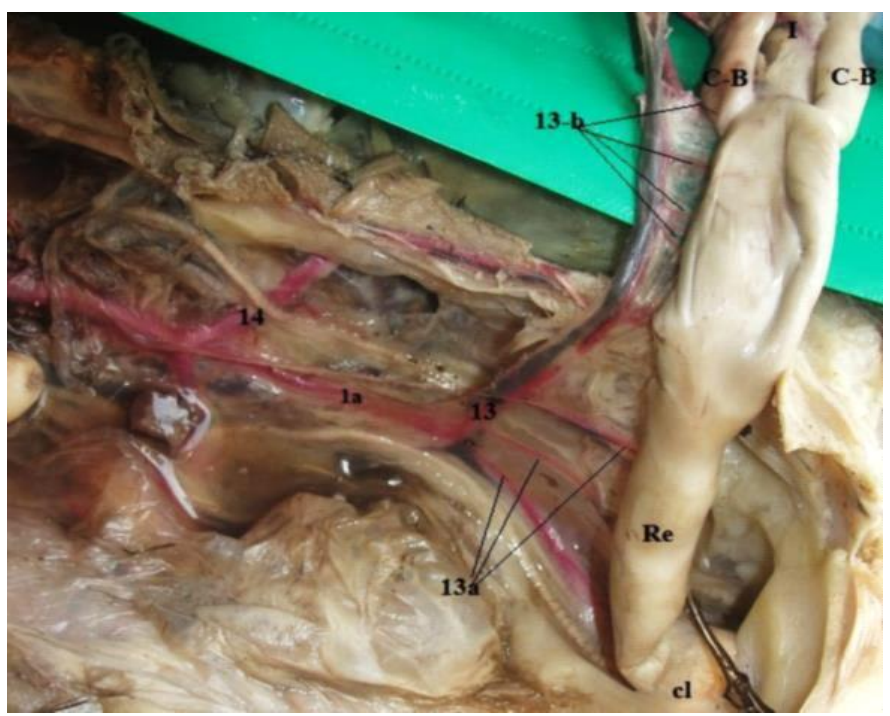

Figure 8. Photograph illustrates blood supply of the large intestine in male turkey. The caudal mesenteric artery supplies the ileum and rectum.C-B: base cecum, R;rectum, , 1a:descending aorta 13: Caudal mesenteric artery,a.: 13a:crainal,13b:caudal group.14: ischiatic a.

$(17,13)$ in cattle egret (Bubulcus ibis), and with (14) in greater flamingo. The celiac artery ramified into two branches including large right ramus of the celiac and large and small left ramus provided the proventiculus and muscular stomach, while the right ramus of the celiac was supplying the ascending limb of the duodenum and continuoued as pancreatic-oduodenal artery. These resutls were in aggrement with those reported in red falcon, 
indigenous ducks, domestic fowls, cattle egret (Bubulcus ibis), and in bulbul (Pycnonotus leucotis) $(10,7,6,13,17)$. However, our results were different from the findings observed in kestrel celiomesentric trunk named cranial mesenteric to supply duodenum in different regions of ascending and descending limbs which is called duodenal branch (11).

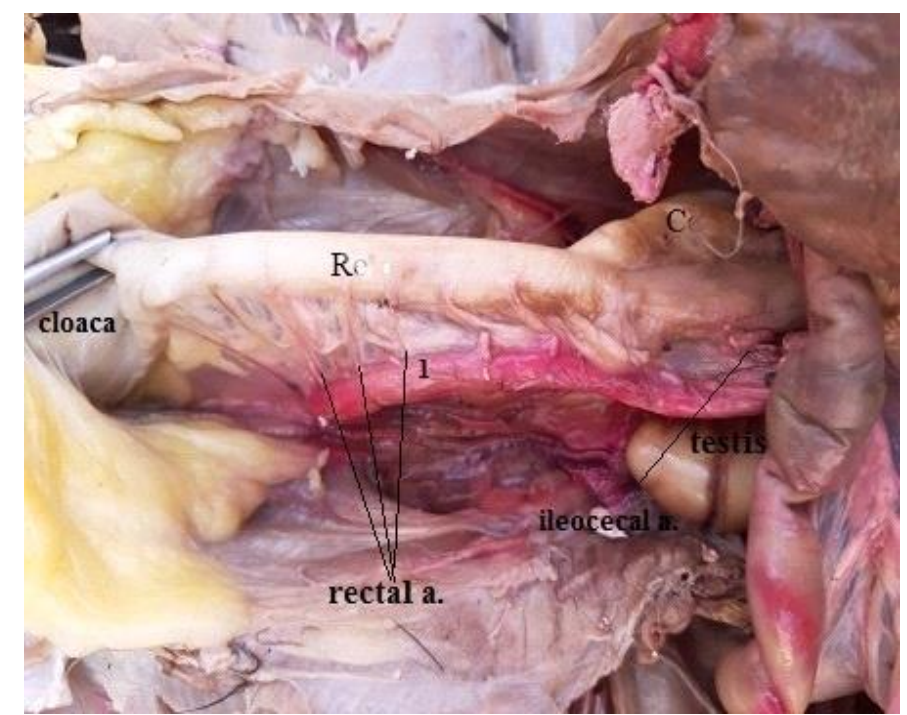

Figure 9. Photograph illustrates caudal mesenteric artery of adult turkey: 1: caudal mesenteric artery, C: ceacum , R: Rectum

The gastroduodenal artery represented by a short vessel raised as one of the terminal branches of the right ramus and continuation of celiac artery which divided immediately into small branches supplying the muscular stomach and the descending limb of duodenum while the jejunum received blood supply by many arteries due to the most nutrients absorption is taken place at the jejunum and thus higher vascularization is needed. The first group was the jejunal arteries originated from cranial mesenteric artery. This finding was similar to that observed by (15) in goose, where the jejunum was supplied by jejunal artery. The present study showed that the proximal portion of the jejunum, at doudenojejunal flexure, was supplied by the jejunal artery, the first branch of celiac artery. This result agreed with $(13,17)$ in cattle egret, and $(11)$ in white-eared bulbul (Pycnonotus leucotis) but differed in what was reported in kestrel (Falco tinnunculus) in which the small intestine of kestrel receive the blood through two main sources namely cranial and caudal mesenteric arteries (11).

The current investigation found that the ileum was a short part of small intestine and received the blood by the ileal artery which raised from two or three branches from right ramus of celiac artery, then ramified with the ileocecal artery which originated from cranial mesenteric artery. Ileocecal branches entered the ileocecal fold, and these results are in agreement with the results of (7) in indigenous duck (Anasplatyrhynchos), (13) in the cattle egret (Bubulcus ibis) and in greater flamingo (Phoenicopterus roseus).

The present study investigated that, the ileocecal artery raised from the right branch of celiac artery and this was similar to cattle egret (Bubulcus ibis) (13), in domestic fowl (6) and in red falcon (10). In greater flamingo (14), it was recorded that ileocecal artery to be arise from the pancreatico-duodenal artery. The present study stated that the last branch of the cranial mesenteric artery supplied the ileum and this was in agreement with what was reported in the pigeon(Columba Livia domestica) and mallard (9).

The cecum received the blood by two ileocecal branches. These results were in agreement with study was done in chicken and goose $(16,6)$. Sometimes it appeared as one branch, in addition to give this artery from a cecal artery that originated from the pancreatico-duodenal artery. This study accepted with (16) in goose and disagree with (13) and (17) in cattle great.

The cranial and caudal mesenteric arteries supply blood to the two ceca and rectum, according to the current analysis. These results were similar to those recorded in goose and chickens (16), white-eared bulbul (Pycnonotus leucotis) (18), cattle egret, and bulbul (Pycnonotus leucotis) $(17,18)$.

The cranial branches extended cranially between the ileum, cecum and supplying the last third of the ileum, and right and left ceca, and by reaching to the ileocecal junction ramified (anastomised) with the caudal branches of the caudal mesenteric artery. In fowl (3) and (17) in cattle egret (Bubulcus ibis).

The blood supply of the small intestine that received the blood by the celiac artery and cranial mesenteric artery. The study of blood supplied of large intestine in adult bronze male turkeys by some branches originated from carinal and caudal mesenteric artery.

\section{ACKNOWLEDGEMENTS}

\section{$\mathrm{N} / \mathrm{A}$}

\section{FUNDING}

These authors declare that above-submitted work was not funded by any governmental or private funding source nor supported by any financial projects.

\section{CONFLICT OF INTEREST}

The authors declare that there is no conflict of interest. 


\section{REFERENCES}

1. Grimes JL, Siope TD. Asurvey of lighting practices in the U. S. turkey breeder industry.J.Appl.Poul.Res. 1999;8 (4): 493-498.

2. Kennamer JE, Brenneman RE, Kennamer JE. Guide to the American wild turkey. National Wild Turkey Federation, Edgefield, South Carolina, USA: Spinger-Verlag;.1986. 1-8p.

3. Getty R, Avian anatomy in anatomy of the domestic animals'.fifth editionPhiladelphia.London,Toronto: B.Saunder co;1975 .18661872p.

4. McLelland JA. Color Atlas of Avian Anatomy.London WCIC, England:Wolfe publishing LtdTarringtonplace; 1990 .48-64p.

5. Whittow GC.SturkiesAvian Physiology. 5th Ed. USA: Academic Press;2000.299-325 p.

6. Rezk HM, El-Bably SH. Gross anatomical studies on theceliac artery in the domestic fowl (Gallusgallusdomesticus).J. Vet. Anat. 2014;7(1);127 - 141

7. Dawood AG. Morphological and histochemical study of small intestine in indigenous ducks(Anasplatyrhynchos)[ thesis]. Baghdad, Iraq:.University of Baghdad; 2013.

8. Khaleel IM,AtieaGD,. Morphological and histochemical study of small intestine in indigenous ducks (Anasplatyrhynchos). IOSRJAVS..2017;10(7);19-27. www.iosrjournals.org

9. Al-Samawy ER .Histomorphological and histochemical comparsion of the stomach and small intestine of the domestic pigeon (Columba Livia domestica), Striated Scope Owl (OtusScorsbrucei) and mallard (Anasplatyrhynchos)[Thesis].Baghdad, Iraq: University of Baghdad; 2015.

10. Haligur A,Duzler A, Course and branch of the celiac artery in the red falcon (Buteorufinus). Veterinari Medicina. 2010; 55 (2): 79-86
11. Al-kafagy SM. Comparative gross and histochemical study between small intestine of adult kestrel (Falco tinnunculus) and whiteeared bulbul(pycnonotusleucotus)[Thesis].Baghdad: University of Baghdad;2016.

12. Ragab SA, Farag FM, Tolba AR, Saleh AA, El-Karmoty AF. Anatomical Study on the Celiac Artery in the Domestic Goose (Anser anser domesticus) with Special Reference to the Arterial Supply of the Stomach. J. Vet. Anat2013; 6(2):23-40.

13. Khalifa EF. Gross anatomical studies on the celiac Artery in cattle Egret (Bubulcus ibis) with special reference to the arterial supply of the stomach. J.Vet.Anat. 2014;7(1) :1-13.

14. Alan A, Duzler A, Orhan I,.Ramification of the celiac artery in the greater flamingo (Phoenicopterusroseus) .Veterinari medicina.2016; 61 (2): 97-101.

15. Besoluk K, Eken E. The arterial supply of Meckels Diverticulum in geese (Anseranserdomesticus).Vet Med Sci. 2001;63(12):13431345.

16. Al-Zaydy SA.A comparative anatomical and histological study on the ceca of chickens and goose[Thesis].Baghdad: University of Baghdad. 2011.

17. El-BablySH. Gross anatomical studies on the arterial blood supply of the intestinal tract of the cattle egret (Bubulcus ibis) .IJARBS .2015; 2(4): 166-176.

18. Salman Rj.Anatomy and histological comparison of the large intestine in adult common kestrel (Falco tinnunculus) and white eared bulbul Pycnonctusleucotis) differ in their food type[Thesis]Baghdad :University of Baghdad; 2016.

19. Amin A, Atiyah AA. Evaluation of general anesthesia induce d by propofol, ketamine protocol in rabbits premedicated with diazepam. Iraqi J Vet Sci.2014;38 (2): 100-107.

\title{
التجهيز الثرياني للأمعاء الدقيقة والظليظة لذكور الديك الرومي البالغ
}

\author{
رباب عبد الامير ناصر 1، و ايمان خليل موسى 2 \\ 1فرع التشريح و الانسجة، كلية الطب البيطري، جامعة ديالى، العر اق، 2فرع التشريح و الانسجة، كلية الطب البيطري، جامعة بغداد، العراق
}

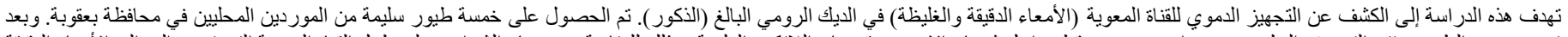

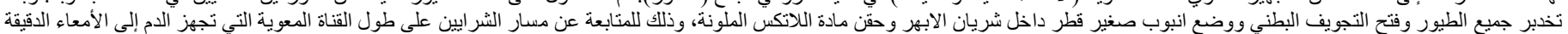

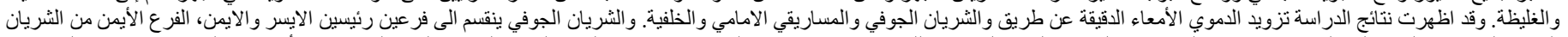

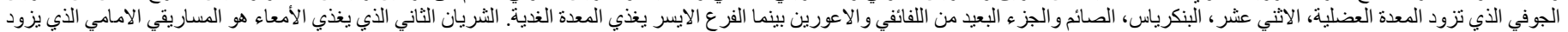

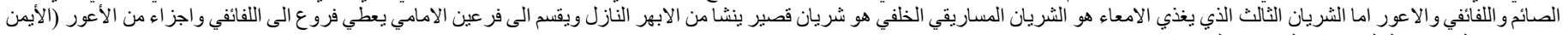
و الايسر ) و المستقيم و الخلفي يغذي المستقيم و المجمع

الكلمات المفتاحية: ديك رومي، الثريان الجوفي، المساريقي الامامي و الخلفي، الأمعاء الدقيقة والغليظة 